\title{
UMA ANÁLISE DA PEDAGOGIA HISTÓRICO-CRÍTICA EM UMA ESCOLA TÉCNICA DE MECÂNICOS DE AERONAVES
}

\author{
GUERRA, Aline Santana Marques ${ }^{1}$ \\ CHIACCHIO, Simon Skarabone Rodrigues ${ }^{2}$
}

GUERRA, Aline Santana Marques; CHIACCHIO, Simon Skarabone Rodrigues. Uma Análise da Pedagogia Histórico-Crítica em uma Escola Técnica de Mecânicos de Aeronaves. Revista Científica Multidisciplinar Núcleo do Conhecimento. Edição 03. Ano 02, Vol. 01. pp 427-442, Junho de 2017. ISSN:2448-0959

\section{RESUMO}

O artigo pretende investigar curso técnico de mecânicos de aeronaves utilizando o olhar da didática histórico-crítica, refletir na ação de contribuir para uma formação crítica, ativa e que realmente oferecesse as condições básicas para a participação e atuação junto ao mercado de trabalho e a sociedade. Utilizou-se como instrumento para pesquisar a reflexão dialógica a fim de investigar uma forma de melhorar a qualidade de suas aprendizagens, através dos métodos da pedagogia histórico-crítica. Evidentemente foi necessário contextualizar historicamente o curso técnico de mecânicos de aeronaves, e focar a presente pesquisa no estudo de seus materiais didáticos e nos resultados estatísticos apresentados pelo órgão do Governo Federal - ANAC (Agência Nacional de Aviação Civil), que constata a ineficiência das aprendizagens teóricas. Ao final da pesquisa percebeu-se a necessidade de direcionar uma possível forma de ensinar que seja mais efetiva por se relacionar com o contexto dos indivíduos, superando seu aparente fracasso escolar.

\footnotetext{
${ }^{1}$ Graduada em Pedagogia pela Universidade Federal de São Carlos UFSCAR.

2 Prof. Dr. no Instituto de Logística da Aeronáutica- ILA, Laureate International Universities e Estácio de Sá, Pesquisador no Programa de Educação: Currículo na Pontifícia Universidade Católica de São Paulo PUC-SP.
} 
Palavras Chave: Didática Histórico-Crítica, Técnico Em Mecânico de Aeronaves, Tecnicismo.

\section{INTRODUÇÃO}

Diante de uma realidade educacional profissionalizante no ensino de adultos no curso de mecânicos de aeronaves, pretende-se refletir neste trabalho sobre os processos de questionamento da formação, da metodologia e da contextualização social que influenciam diretamente este setor educacional.

Foi abordado o contexto histórico do curso de mecânicos de aeronaves, apontando o tecnicismo como didática predominante, discorre-se também sobre a pedagogia histórico-crítica, que contrapõe e apresenta uma possibilidade para modificação de uma situação de aparente fracasso escolar.

Como elemento básico na construção do trabalho, foi necessária a leitura de documentações específicas da ANAC (Agência Nacional de Aviação Civil) e dos materiais didáticos que viabilizam a percepção de uma aprendizagem mecânica e verbalista que resulta em uma grande porcentagem de alunos que apresentam insucesso na busca de sua certificação no órgão competente (ANAC), por isso, surgiu um questionamento sobre qual didática poderia fazer frente a tal realidade e necessidade.

Discorre-se sobre a época de maior crescimento da educação profissional - a década de 1960 e 1970, que aumentou vertiginosamente em resposta ao crescimento industrial e ao pensamento desenvolvimentista.

Segundo Jacometti $\left(2008\right.$, p.3) "a lei $n^{\circ} .5 .692 / 71$ obrigou todas as instituições de $2^{\circ}$. Grau a ofertarem o curso profissionalizante integrado", implantando assim uma formação profissional de massa, com os princípios de economicidade, eficácia e eficiência, tornando a escola como uma pequena indústria que prepara os alunos para serem trabalhadores conformados e aptos ao mercado de trabalho. 
Além disso, o autor ainda salienta em relação às legislações educacionais brasileiras afirma em seu artigo que:

[...] por ocasião do sancionamento das duas LDBs consideradas: 1971 e 1996, não se diferenciam e caracterizam-se como neoliberais e que as pressões contextuais coercitivas e normativas vêm afetando significativamente as transformações ocorridas na educação profissional brasileira (JACOMETTI, 2008. p.8)

Diante do exposto, a legislação brasileira não combate o caráter tecnicista, perpetuando a formação profissional que exclui socialmente os operários.

A falta de contextualização e socialização dos conhecimentos refletiu e projetou uma educação elitista e excludente, classificatória e que não trouxe escolarização e acesso às classes menos favorecidas, além de propiciar uma formação alienante de baixo rendimento. Tal situação também é agravada por existir um distanciamento entre a teoria e a prática, ocasionando a não aprendizagem efetiva, por não valorizar os saberes da experiência e vivência em determinados setores e atividades (ALVES, 2015, p.65).

Ainda sobre o trabalho, é utilizado o olhar da abordagem dialógica, que é uma metodologia da pedagogia histórico-crítica, onde esta propõe uma educação que questione os determinismos sociais impostos na escola, através do diálogo, a proatividade e intencionalidade do professor quando elabora um plano de aula (SAVIANI, 2013).

Acredita-se em um ensino que não exclui a exposição de conteúdo, mas que os contextualiza segundo a realidade e interesse desses, objetivando uma aprendizagem efetiva.

Por isso uma parte da fundamentação bibliográfica do trabalho foi realizada por meio da pesquisa de alguns autores que refletem sobre a pedagogia histórico-crítica.

O primeiro a propor tal pedagogia foi Saviani (2013), pioneiro na utilização e na conceitualização dessa, correspondendo a um anseio, uma resposta frente à dois 
fenômenos educacionais: a) corrente tecnicista educacional da década de 1970 e 1980 e b) as teorias critico-reprodutivistas que se restringiam a compreender as relações sociais.

O autor propõe uma educação de cunho histórico dialético, em que haja uma possibilidade de se articular, como uma proposta pedagógica cujo ponto de referência, seja a transformação da sociedade e não sua manutenção, a sua perpetuação, sem que seja também deixada de lado a intencionalidade da ação educacional mediante uma atuação sistemática, planejada e que exige a competência técnica dos educadores, só que voltados para a socialização dos saberes e não somente a mera transmissão dos conhecimentos descontextualizados.

Avançando na utilização dos métodos da pedagogia histórico-crítica como proposta de pesquisa, temos Gasparin (2015), que já nas primeiras páginas de seu livro "Uma Didática para a Pedagogia Histórico-Crítica" afirma refletir e operacionalizar uma forma prática para os conceitos elaborados de Saviani.

Até o momento, no ano de 2012, quando esta obra foi escrita, o assunto havia sido muito discutido no meio educacional, no entanto havia a necessidade de uma organização dos métodos dessa pedagogia, a fim de nortear as ações educativas dos educadores que desejassem utilizá-lo. Assim em sua obra, Gasparin (2015) desenvolveu uma proposta onde "toma-se como marco referencial epistemológico a teoria dialética do conhecimento, tanto para aprofundar a concepção metodológica e o planejamento de ensino-aprendizagem, com a ação docente-discente" (GASPARIN, 2015, p.3).

Assim se propõe aqui a prática dialética que incorpora os passos de "prática social, teorização, problematização, instrumentalização e segunda prática social" (GASPARIN, 2015, p.2). Enquanto que Saviani (2015, p.81) discuti o caráter teórico e conceitual da pedagogia histórico-crítica, Gasparin $(2015$, p.2) procura uma aplicação e viabilização desta teoria, propondo inclusive um modelo de plano de aula constante no final de sua obra. 
Do processo de prática social para a teorização Gasparin (2015, p.7) afirma que de maneira que "a teorização possibilita, então, passar do senso comum particular, como única explicação da realidade, para os conceitos científicos e juízos universais que permitem a compreensão dessa realidade em todas as suas dimensões". Por isso, internalizando esta teoria, transforma sua prática que passa a ser orientada. $\mathrm{O}$ pensador passa a ser atuante, no processo ação-reflexão-ação.

Observa-se que tanto o autor Corazza (1991) quanto Gasparin (2015) afirmam que este movimento dialético que conduz a aprendizagem se dá no seio das práticas sociais, concebendo que o conhecimento perpassa o contexto histórico em que foi construído, como foi transformado e no processo de reflexão sobre esse todo (GASPARIN, 2015).

Assim, o processo utilizado altera a práxis do pesquisador, à medida que cria novos significados dos saberes sistemáticos e que nesse movimento dialético produzirá uma interpretação própria, que interage com os saberes provenientes da experiência, e que desenvolve um novo sentido de didática.

Não se pretende aqui esgotar o assunto, nem de determinar as vias didáticas estudadas como única forma de se ensinar, visto que a própria concepção da pedagogia estudada valoriza a individualidade do aluno, do grupo a que pertence, do educador e da situação de aprendizagem que se apresenta com suas características sociais e históricas próprias (VARGAS \& GOMES).

\section{CONTEXTO HISTÓRICO DO CURSO DE MECÂNICA DE} AERONAVES

No Brasil, antes de 1988, não havia uma regulamentação específica para a formação de mecânicos de aeronaves. Só após a criação do CINDACTA, em 1988, que se começou um movimento para a formação e estruturação desses cursos técnicos. A própria ANAC só foi fundada em 2005, com a promulgação da Lei 11.182, o que ocasionou o surgimento das regulamentações e fiscalizações por um órgão específico do Governo Federal na área da aviação civil (ANAC, 2007). 
Assim, sofrendo uma reestruturação e unificação pedagógica, foi montada uma coletânea de matérias e materiais didáticos para a instrução desses profissionais. $\mathrm{O}$ caráter tecnicista fica marcado porque todo material didático foi baseado em uma tradução literal do material do FAA (Federação Americana de Aviação), de distribuição obrigatória e mandatória a todas as escolas que formavam teoricamente. Além disso, para que a instituição de ensino fosse homologada (autorizada a lecionar) pela ANAC teria que seguir essas instruções técnicas e cumprir a ministração do conteúdo necessário para a prova teórica utilizando um conteúdo padrão.

Foi consultada a legislação que rege a didática, o curso e as exigências de proficiência em torno do ensino técnico de mecânicos de aeronaves que são regulamentados e escritos pela ANAC, representada pela RBHA (Regulamento Brasileiro de Homologação Aeronáutica) de número 65 , que trata dos requisitos para se adquirir a Certificação de Conhecimento Teórico (CCT) e que cita os pré-requisitos necessários, incluindo a lista de matérias teóricas obrigatórias; e a RBHA 121, tratando especificamente do treinamento e dos requisitos para a atuação aeronáutica.

Atualmente, apesar de aumentar a fiscalização pelo órgão específico - a ANAC - e também responsável por manter a qualidade e qualificação profissional no âmbito da aviação não se observa mudanças e atualizações no material didático-metodológico nos cursos teóricos, pois os mesmos não acompanharam as atualizações tecnológicas, e a tradução do material continua a mesma que a feita na década de 1980.

\section{CONTEXTO HISTÓRICO DA PEDAGOGIA HISTÓRICO-CRÍTICA}

Para citar a história da pedagogia histórico-crítica, a primeira referência a ser utilizada é o livro Pedagogia Histórico-Crítica, de Dermeval Saviani. Nessa obra o autor situa o início desse tipo de pedagogia, que surgiu de uma necessidade frente à pedagogia tecnicista praticada a partir da década de 60, especialmente no período do Regime Militar, que objetivava aumentar a eficiência da educação, além de formar cidadãos conformados às normas sociais e bons profissionais e operários. Tal sistemática e a postura do docente são explicados por Saviani (2015, p.103), quando afirma 
[...] a partir da reforma implantada pela Lei 5,692/71, a organização da rede escolar enfatizou a importância dos especialistas, situando o corpo docente na condição de executores dos planos e programas formulados pelos técnicos e por eles supervisionados.

Criticando as teorias tecnicistas e tradicionais surgem as teorias críticoreprodutivistas, que buscaram compreender como acontecia os mecanismos de reprodução ideológica que se instalou através de ideais que mantém uma classe dominante no poder - a burguesia, chamado por Baudelot e Establet de "violência simbólica" (GADOTTI, 1999, p.189), e que consideram a escola como "aparelho ideológico do estado" (SAVIANI, 2015, p.113).

No entanto, as teorias crítico-reprodutivas se limitavam apenas à compreensão da realidade e determinação desses mecanismos de controle. Refletindo sobre essa questão, podemos encontrar nas palavras de Gadotti (1999, p.189):

Bourdieu e Passeron desenvolveram a teoria da reprodução baseada no conceito de violência simbólica. Para eles, toda ação pedagogia é objetivamente uma violência simbólica enquanto imposição, por um poder arbitrário. A arbitrariedade é a cultura dominante. O poder arbitrário é baseado na divisão da sociedade em classes. A ação pedagógica tende à reprodução cultural e social simultaneamente. (GADOTTI, 1999, p.189).

Assim, Saviani (2015) continua discorrendo o efeito das teorias crítico reprodutivas no Brasil. Por isso, houve a tentativa de mudança da realidade reprodutivista através da revolução social pela revolução cultural, que fracassou. Estudando o motivo de tal fracasso, os teorizadores crítico-reprodutivistas chegaram na conclusão que "só se pode mudar a cultura mudando as bases da própria sociedade" (SAVIANI, 2015, p.114).

Não havia uma proposta de orientação didática e efetiva para a aplicação na atual situação do Brasil, que estava em meio ao Regime Militar e do sistema educacional tecnicista; por isso, a pedagogia histórico-crítica foi sendo concebida, através de 
diversas discussões no interior das universidades. $O$ autor explica que o desenvolvimento da teoria histórico-crítica inicialmente foi chamada de dialética, pois propõe uma didática que contextualiza a aprendizagem, considerando a cultura, a história e a sociedade em que é produzida.

Saviani (2015) também não deixou de lado a competência técnica e o saber-escolar, fator que viabiliza a mediação adequada das aprendizagens aos alunos, pois viabiliza que eles adquiram conhecimentos necessários para atuar socialmente; e, no âmbito da presente pesquisa, crucial para que sejam capazes de se tornarem aptos na prova de proficiência da ANAC.

Já avançadas as discussões nos congressos e obras que escreveram sobre o sócioconstrutivismo, tem-se o autor que deu continuidade ao trabalho de Saviani (2015) foi Gasparin, que estudou e escreveu sobre uma metodologia para essa pedagogia.

\section{A DIDÁTICA DA PEDAGOGIA HISTÓRICO-CRÍTICA -UMA POSSIBILIDADE PARA O CURSO TÉCNICO DE MECÂNICOS DE AERONAVES}

Como possível didática tem-se a pedagogia histórico-crítica, interagindo racionalmente sobre o sistema apostilado e de exposição verbal utilizada nas aulas do curso de mecânicos de aeronaves.

As reflexões e concepções da pedagogia citada acima ainda carecem de maiores sistematizações, ampliando seu campo para a aprendizagem de adultos, por exemplo. E em busca de uma orientação de "como fazer" a pedagogia histórico-crítica, adotouse o estudo da obra "Uma didática para a Pedagogia Histórico-Crítica", escrito por João Luiz Gasparin (2015), que é uma continuação das ideias de Saviani, segundo relato do próprio autor.

A obra inicia-se questionando o papel da educação e sua significação, assim afirma: 
[...] se a aprendizagem dos conteúdos por parte dos alunos significou, por muito tempo, um requisito para obter uma boa nota numa prova ou exame a ser promovido, agora uma nova dimensão deve ser considerada: qual a finalidade social dos conteúdos escolares? (GASPARIN, 2015, p.13)

Se for trazido para a realidade da aprendizagem em escolas técnicas, não basta memorizar conteúdos para poder passar na prova de proficiência, os conteúdos também têm um papel social.

Diante do exposto Gasparin (2015) ainda sugere uma nova postura do professor e dos alunos, que sob a perspectiva da pedagogia histórico-crítica focam a aprendizagem com uma função teórico-prática, tendo um plano de fundo o aspecto social.

A abordagem dos conteúdos de forma contextualizada faz com que os alunos compreendam que todo conhecimento são parte de uma produção histórica, favorecendo várias compreensões sobre um conteúdo.

Gasparin (2015) adota cinco passos para a os procedimentos operacionais da ação docente-discente: a prática social, onde se enunciam os conteúdos, dialogando com os alunos; a problematização, onde se é questionado os conhecimentos trazidos pelos alunos, direcionados ao conteúdo que o professor quer explanar; a instrumentalização, a teoria, onde serão confrontados os conhecimentos iniciais dos alunos pelos conhecimentos científicos trazidos pelo educador; a catarse, que é a síntese mental do aluno sobre o assunto mediante o conteúdo ministrado e as interações sociais e práticas; e, por último a prática social final, que demonstra as dimensões trabalhadas pelo grupo.

Discorrendo um pouco mais sobre as estratégias abordadas na obra, primeiramente temos a prática social, onde o educador desafia os alunos são mobilizados e sensibilizados, utilizando elementos do cotidiano dos alunos para ligá-los ao conteúdo técnico a ser ministrado. É também uma sondagem, pois os alunos podem expressar 
se possuem alguma noção da matéria abordada e em que profundidade (GASPARIM, 2015, p.15).

Exemplos cotidianos não faltam, pois, a maioria dos elementos técnicos e práticos automotivos também é utilizada na aviação. Temos como exemplo que pode ser utilizado a bateria chumbo-ácida, tópico da matéria de Eletricidade Básica, que é utilizada tanto em carros quanto em aeronaves.

A importância da prática social inicial repousa sobre o fato de ser o elo para as posteriores apresentações da matéria, além disso, desperta os alunos para a importância do que será ministrado, quanto à sua atuação profissional e seu conhecimento sobre o assunto.

Nesse momento, além de ouvir os alunos sobre o tema da aula, o professor reafirma sua importância, anota as percepções sobre os mesmos e lança mão de vídeos, peças de aeronaves, fotos ou qualquer outro recurso que os estimule para o conteúdo.

Esse passo inicial também traz um conhecimento para o educador que delineia seu planejamento escolar, saindo de sua zona de desenvolvimento atual - teoria vygotskyana utilizada também na obra de Gasparin - direciona os planos para tornar o senso comum e empírico dos alunos em técnica e científica.

O planejamento, considera um "processo pedagógico escolar intencional, que precisa ser orientado pela previsão do que se pretende alcançar", e "conta com duas dimensões básicas: o que aprender e para que aprender" (GASPARIN, 2015, p. 24).

Também apresenta o que será abordado na matéria, abrindo assim outro passo, a problematização. Para Gasparin (2015, p. 35) “... a problematização é um elementochave na transição entre a prática e a teoria, isto é, entre o fazer cotidiano e a cultura elaborada. É o momento em que se inicia o trabalho com o conteúdo sistematizado".

Nesse ponto incide as principais questões que devem ser resolvidas por alunos e professores que tem relevância social e na carreira profissional que estão construindo quando se propuseram a fazer o curso em estudo. 
Deve se destacar que o planejamento e a seleção de conteúdos não deveriam ser colocados de forma rígida, mas tomado com base ao grupo de alunos que se apresenta, o que, por diversas vezes, se difere sensivelmente da proposta de conteúdo, das ementas das disciplinas dos módulos, apresentas pela ANAC.

Não é recomendado que se exclua os conhecimentos pré-concebidos, mas que se discuta-os com os alunos quanto a sua importância social e profissional: Assim se questiona: por que devo aprender nessa matéria?

Além disso, esses não podem ser trabalhados de forma individual, como se os temas abordados fossem concebidos isoladamente, mas sim considerando que surgiram de uma necessidade social, histórica e humana, e que assim se produz também tecnologia e profissionalização.

Depois do planejamento, temos a Instrumentalização, um momento de construção do conhecimento científico realizado por docentes e alunos.

Os educandos e o educador agem no sentido da efetiva elaboração interpessoal da aprendizagem, através da apresentação sistemática do conteúdo por parte do professor e por meio da ação intencional dos alunos de se apropriarem desse conhecimento (GASPARIN, 2015, p.50).

Esse movimento em direção à aprendizagem é predominantemente intrapessoal, pois os objetos expostos, a matéria, os textos, as imagens e vídeos ganham um novo significado dado pelo próprio aluno, ampliando sucessivamente e não-linearmente 0 conhecimento anterior.

Nesse instante, tudo influi nessa fase: as dificuldades, a cultura, a escolarização pregressa e como foi essa escolarização, que pode ou não ter incutido um preconceito a respeito da matéria de exatas, por exemplo, que é indispensável para a compreensão das matérias de Eletricidade Básica, Sistemas Elétricos e Motores à Reação, abordados nos módulos básicos e Grupo Motopropulsor respectivamente. 
A instrumentalização é o caminho pelo qual o conteúdo sistematizado é posto à disposição dos alunos para que o assimilem e o recriem e, ao incorporá-lo, transformem-no em instrumento de construção pessoal e profissional (GASPARIN, 2015, p.51).

Sobre as possibilidades de aprendizagens e estratégias de aulas, temos que a teoria construtivista de Vigostky citada por Gasparin, aborda os conceitos de zona de desenvolvimento proximal do aluno como condições para o planejamento e a instrumentalização de aula, de modo que as várias metodologias e a interação social possibilite ao aluno que internalize o conhecimento externo, transformando seus conceitos inicialmente originados do senso comum em conhecimentos sistematizados.

Uma das estratégias no caso do curso de mecânica de aeronaves é a utilização de conceitos associados com imagens visuais e equipamentos, o que torna a assimilação dos temas técnicos da aviação mais fácil. Tais recursos são direcionados a se relacionar e responder as questões levantadas na problematização.

Ainda sobre a atuação docente, segundo Perrenoud (1999), o professor que é um mediador possui um tipo de competência docente que se chama "Conceber e fazer evoluir os dispositivos de diferenciação". O mesmo pode fazer perguntas do tipo: qual a diferença entre o motor de partida de um carro que vocês exemplificaram e o motor de partida da aeronave que falei agora? Assim, o aluno pode diferenciar e caracterizar um determinado equipamento, por suas similaridades e diferenças, além de construir um conceito geral de motor elétrico, por exemplo.

Ao término do processo de instrumentalização, utilizando os diversos instrumentos de atribuição social e histórica do aluno, temos que "o desenvolvimento dos conceitos científicos tem início na esfera do caráter consciente e da voluntariedade, descendo à experiência, pelo empírico" (GASPARIN, 2015).

Seguindo os passos do autor tem-se a catarse, que é a manifestação do aluno quanto o que compreendeu dos processos de interação social e de instrumentalização - uma 
síntese. Nesse momento, o aluno é convidado a demonstrar que seu conhecimento empírico, prático e caótico se tornou situado historicamente com um olhar científico, mas construído pelo mesmo.

No último passo, tem-se a prática social final, que o momento onde o aluno se posiciona frente os conteúdos que lhe foram mediados utilizando o conteúdo técnico, a vivência social e a mediação do professor.

Para Perrenoud, as competências educacionais (essenciais para um ensino mais efetivo) são habilidades de mobilizar recursos físicos e mentais, com esquemas mentais complexos, de acordo com o cenário de sala de aula que se apresenta, ou seja, é situacional. Assim, difere-se da prática atual, pois lança mão de uma construção de aprendizagem com o aluno.

\section{RESULTADOS E DISCUSSÃO DA COLETA DE DADOS ESTATÍSTICOS SECUNDÁRIOS NA ANAC E ANÁLISE DO MATERIAL DIDÁTICO}

Dado os contextos históricos citados anteriormente, foi realizada também uma coleta de dados secundários, segundo as estatísticas oficiais da ANAC. Percebe-se assim que os índices apresentados pela ANAC deslumbram uma realidade muito alarmante de exclusão dos alunos que se propõe a realizar o curso de mecânicos de aeronaves, segundo o exemplo explicitado pelo gráfico abaixo: 


\section{Procentagem de Alunos Aprovados, Reprovados e Faltosos em 2015}

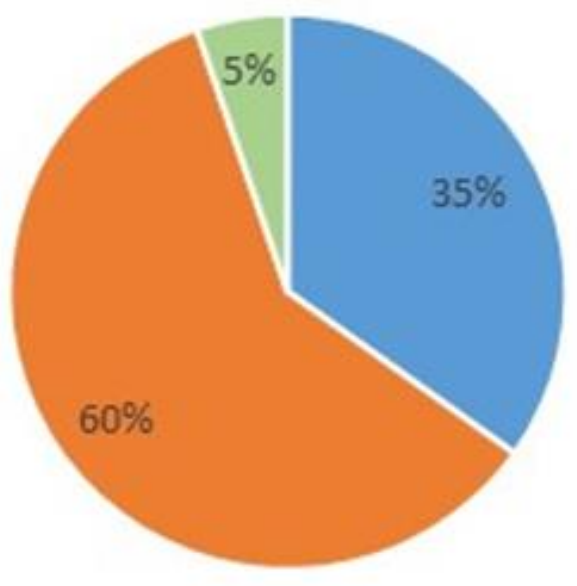

\section{" Aprovados " Reprovados $=$ Faltosos}

Gráfico 1 - Fonte: ANAC 2015

É possível perceber que mais de $60 \%$ dos 5.160 inscritos no ano de 2015 não passaram no exame teórico que habilita a certificação de CCT, ou seja, mesmo com certificado que comprova a realização do curso teórico nas escolas homologadas pela ANAC esses alunos não obtiveram sucesso, não podendo exercer legalmente a profissão de mecânicos de aeronaves.

Os dados também representam um indício de possível fracasso escolar. Esse conceito é extremamente complexo, sendo considerado por Palma, como:

[...] um fenômeno social produzido historicamente, circunscrito por determinantes de ordem socioeconômica, cultural, política e pedagógica, os quais simultaneamente atravessam o coletivo social e a singularidade do sujeito, ou seja, consideramo-lo uma problemática que afeta toda a sociedade, sociedade esta, atualmente, marcada por valores que privilegiam o poder e o dinheiro, considerados, por muitos, como indicadores de sucesso social (PALMA, 2007, p.23). 
Entretanto, devido à necessidade de se restringir o processo de pesquisa neste documento à análise de dados secundários, temos que a reflexão sobre fracasso escolar seja focada às características apontadas nos dados coletados em órgãos oficiais, sem que se englobe o relato dos alunos ou uma pesquisa com os mesmos para delinear um perfil social e cultural.

Mesmo assim, a alta porcentagem de alunos reprovados no exame deveria causar um replanejamento das ações pedagógicas no curso técnico de mecânicos de aeronaves, para que essa quantidade de reprovações diminuísse.

Acreditamos que os fatores mais evidentes que motivam o resultado apresentado anteriormente sejam: o material didático apostilado de baixa qualidade, defasado com a atualidade e que replica a apostila americana do final da década de 1980 e a falta de contextualização dos conteúdos ministrados com algum conhecimento cotidiano dos alunos.

Destrinchando os pontos acima, o material didático é apresentado como apostilas, separadas em módulos (Grupo Motopropulsor, Célula e Aviônica) e depois em matérias constantes no currículo mínimo do RBHA estipulado pela ANAC. Percebese que ainda se aborda o assunto de ferramentas manuais que já estão em desuso há duas décadas, mas que, no entanto, ainda são exigidas a leitura de suas descrições para realização de avaliações de múltipla escolha na escola.

A apostila também não possui figuras coloridas, nem fotos dos equipamentos ou de onde são instalados. Os esquemas elétricos, no caso da matéria de Sistemas de Partida, por exemplo, são mal desenhados, de difícil compreensão, mesmo que sejam explanados com o auxílio do educador, conforme exemplo da figura abaixo: 

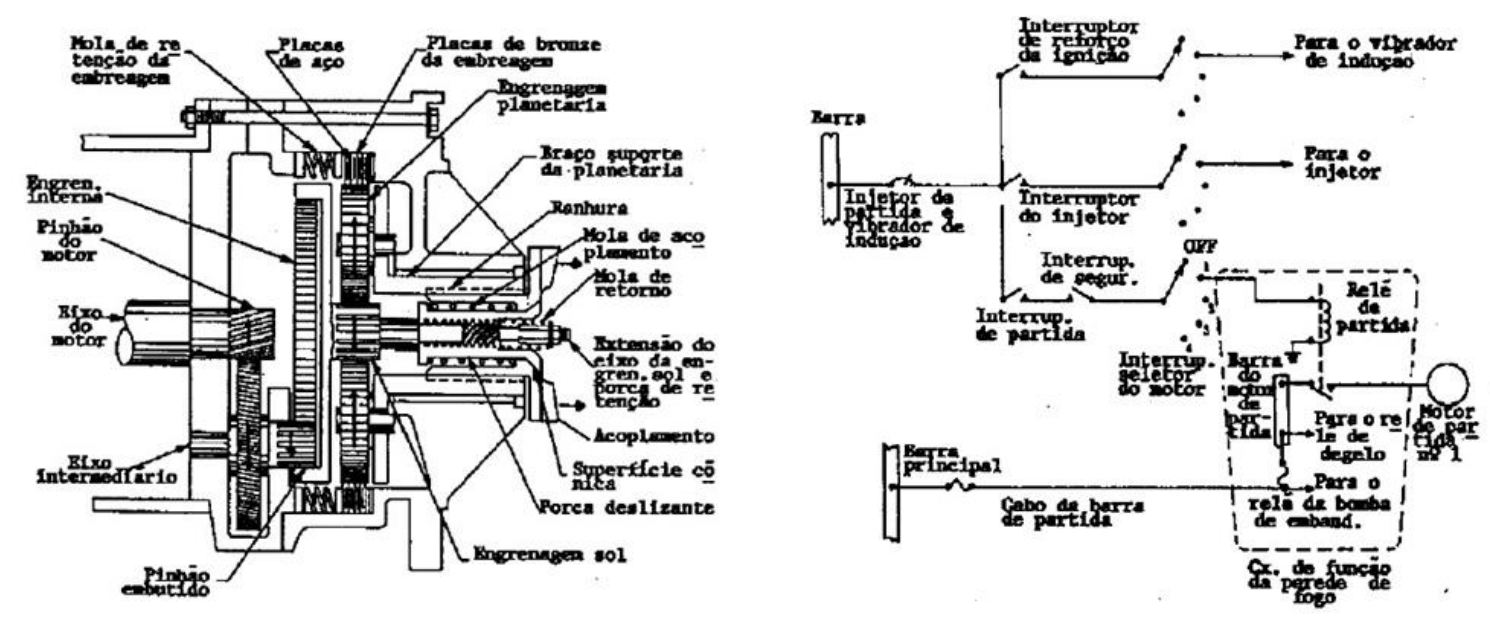

Figura 1 - Fonte: Apostila

O conteúdo em muitas apostilas não segue uma progressão lógica. Tomando novamente como exemplo a apostila de Sistema de Partida (que é ministrada no módulo de Aviônica), e uma amostra de seu texto, primeiro o autor cita os motores de partida elétrico para grandes motores de aeronaves, depois para pequenos motores de aeronaves e posteriormente volta para a explicação dos motores de partida para grandes motores de aeronaves, ou seja, isso pode ocasionar falta de clareza e compreensão do texto técnico, o mesmo não escreve com continuidade.

Ainda, sobre a falta de contextualização com o cotidiano dos alunos, temos que em nenhum momento o autor da apostila importa-se em utilizar algum exemplo usual ou comum, ou que ainda em sua fala textual possa comunicar-se com o leitor. A linguagem é direta, sem clareza, e na maioria das matérias sem progressão de lógica, como se fosse um texto lançado de qualquer forma ao leitor, que não respeita suas possíveis dificuldades ou em adequar o conteúdo técnico à uma forma didática e compreensível de passar o conhecimento.

A cerca da didática aplicada no curso em questão, a reflexão sob o prisma da didática histórico-crítica torna-se uma superação do paradigma tecnicista, aja vista que "o desenvolvimento dos conceitos científicos tem início na esfera do caráter consciente e da voluntariedade, descendo à experiência pessoal e ao concreto, que tem o sentido determinado pela experiência, pelo empírico" (GASPARIN), ou seja, o conhecimento 
técnico essencial para familiarizar os alunos com sua futura atuação no trabalho extrapola os limites da transmissão mecânica e unidirecional, passando a ter um significado real para o aluno por se relacionar com sua vida.

Com o enfoque em alunos adultos, que fazem parte dos estudantes do curso técnico de mecânicos de aeronaves, pode-se perceber que os mesmos já possuem suas funções psicológicas superiores desenvolvidas, no entanto, presume-se que em muitos casos não foi desenvolvida as concepções técnico científicas, pelo fato da observação do alto índice de reprovação da prova de proficiência da ANAC. Esse conceito apresentado anteriormente faz parte da teoria do construtivismo de Vygotsky (2001, p.224), essa que também foi utilizada da a feitura da teoria da didática históricocrítica de Gasparin (2015).

\section{CONCLUSÃO}

Assim estudar o contexto escolar e como esse se construiu histórico/socialmente pode "orientar as ações", apontando para o planejamento e prática educacional que se divide nos seguintes processos explicitados: prática social, problematização, instrumentalização, catarse e nova prática social, ou seja, o planejamento de aula baseado nesses processos pode favorecer o modo com o qual os alunos fazem sua prática social, a compreensão de mundo e comunidade, oferecendo-os a oportunidade de tornar-se críticos.

No papel de educadores, a intenção é de racionalizar formas de favorecer aprendizagens mais significativas aos alunos adultos, tornando-os mais inclusos, combatendo os determinismos sociais históricos que causaram a exclusão social de diversos grupos sociais de pessoas menos favorecidas.

A urgente necessidade de se formar utilizando métodos mais humanos e que combatesse o processo de alienação social traz à tona o estudo do materialismo dialético, que mergulha na realidade em que se propõe a mudar, interagindo e encontrando novas formas do fazer docente e da formação do aluno, onde ambos aprendem, se adaptam em suas especificidades e internalizam novos conhecimentos. 
O estudo da aprendizagem profissional de adultos carece de mais discussões sobre sua práxis, visto que a cada fase da vida humana têm-se desenvolvimentos, experiências e formas de aprendizagens diferentes.

Além disso, a respeito do método de transmissão do conhecimento teórico, Vigotsky rechaça a simples memorização, sem contextualização, que faz parte do processo de transmissão do conhecimento na didática tecnicista.

Tudo isso colabora para a observação que atualmente a queixa mais comum no meio educacional quanto ao ensino de adultos é a formação pregressa deficitária e a falta de postura participativa em sala de aula, que dificultam o processo de aprendizagens de novos conteúdos e novos saberes.

Para modificar esse cenário há de se quebrar esse paradigma, mobiliando as mentes e os ânimos em prol e um novo fazer na escola. Por isso analisou-se os dados de alunos aprovados e reprovados, além da reflexão sobre a educação tradicional.

Em busca de uma nova maneira de interagir com o ensino, conclui-se que o estudo, a reflexão e o planejamento baseados em uma pedagogia histórico-crítica aparentam criar condições e oportunidades de uma aprendizagem dos "saber-escolares", isto é, seleção de conhecimentos, competências, habilidades e conteúdos necessários para a atuação política, social, profissional e humana dos alunos dentro de seu espaço próprio para o desenvolvimento dessas atividades - a escola.

Assim, aprofundando-se na aplicação da pedagogia histórico-crítica na educação profissional, percebe-se que a mesma deve abordar conteúdos sistematizados, permeados de uma organização sistemática dos conhecimentos científicos, mediados pela competência técnica do educador, que intencionalmente discute dialogicamente com o aluno os conhecimentos, promovendo a prática social, contextualizada e historicamente situada, para que se criem vínculos culturais e se forme além de um aluno capaz de atuar profissionalmente, que detenha conhecimentos técnicocientíficos, seja crítico, atuante e adquira competências que não advém de uma educação verbalista, tradicional, mas sim de uma prática social. 


\section{REFERÊNCIAS}

AGÊNCIA NACIONAL DE AVIAÇÃO CIVIL. Despachante Operacional de Voo e Mecânico de Manutenção Aeronáutica. Regulamento Brasileiro de Homolagação Aeronáutica № 65. Portaria 802/DGAC, de 15 de maio de 2001, publicada no DOU de 15 de junho de 2001.

AGÊNCIA NACIONAL DE AVIAÇÃO CIVIL. Histórico. Disponível em: http//www.anac.gov.br. acesso em:18/08/2016.

AGÊNCIA NACIONAL DE AVIAÇÃO CIVIL. Requisitos Operacionais: Operações Domésticas, de bandeira e suplementares. Regulamento Brasileiro de Homolagação Aeronáutica № 121. Resolução no 146, de 17 de março de 2010, publicada no Diário Oficial da União № 54, S/1, p. 16, de 22/03/2010.

AGÊNCIA NACIONAL DE AVIAÇÃO CIVIL. Sistemas de Partida e Ignição. Disponível em: http//www.anac.gov.br. acesso em:18/08/2016.

BRASIL. Lei no 5.692/71 de 11 de agosto de 1971b. Diretrizes e Bases para o ensino de $1^{\circ}$ e $2^{\circ}$ graus, e dá outras providências. Disponível em: http://www2.camara.gov.br/legislacao/publicacoes/republica.

BRASIL. Lei 11.182 de 27 de setembro de 2005. Criação da Agência Nacional de Aviação Civil. Disponível em: < http://www2.anac.gov.br/biblioteca/leis/lei11182.pdf>. Acessado dia 09 de setembro de 2016.

CORAZZA, Sandra Mara. "Manifesto por uma dialética". Contexto e Educação, ljuí, vol. n. 22, 1991.

DURAN, Marília Claret Geraes; ALVES, Maria Leila; PALMA FILHO, João Cardoso. Vinte anos da política do ciclo básico na rede estadual paulista. Cadernos de Pesquisa, São Paulo, v. 35, n.124, p.33-42, jan/abr., 2005. 
EUA. Department of Transportation Federal Aviation Administration Certification and Operations Domestic, Flag, and Supplemental Air Carriers and Commercial Operators of Large Aircraft. In: Code of FEDERAL Regulations. Washington, 01 de janeiro de 1988, Title 14, Part 65.

GASPARIN, João Luiz. Uma Didática para a pedagogia histórico-crítica. 3.ed. Campinas: Autores Associados, 2005.

GADOTTI, Moacir. História das Idéias Pedagógicas. 8ª ed. São Paulo: Ática, 2015.

JACOMETTI, Marcio. Reflexões sobre o contexto institucional brasileiro contemporâneo e as transformações na educação profissional. In: Revista Educar, Curitiba, n. 32, p. 233-250, 2008. Editora UFPR

LIBÂNEO, José Carlos. Organização e Gestão da Escola - Teoria e Prática. São Paulo: Heccus editora, 2015.

MARIGO, A. F. C. BRAGA, F. M. Em busca do conhecimento em educação fundamentos do trabalho acadêmico-ciêntífico. São Carlos: EdUFSCar, 2001.

PALMA, Rejane Christine de Barros. Fracasso escolar: Novas e Velhas Perspectivas para um problema sempre presente. Londrina: 2007.

PERRENOUD, Philippe. Dez novas competências para ensinar. Porto Alegre: ArtMed, 2000.

SAVIANI, Demerval. Pedagogia Histórico-Crítica. 11를. Campinas: Autores Associados, 2013.

VARGAS, Patrícia Guimarães, GOMES, Maria de Fátima Cardoso. Aprendizagem e desenvolvimento de jovens e adultos: novas práticas sociais, novos sentidos. Disponível em < http://www.scielo.br/scielo.php?script=sci_arttext\&pid=S151797022013000200011 >. Acessado dia 16 de abril de 2016. Educ. Pesquisa, São Paulo, v. 39, n. 2, p. 449-463, abr./jun. 2013. 
VIGOTSKI, L. S. A construção do pensamento e da linguagem. São Paulo: Martins Fontes, 2000. 